\title{
DOENÇA RENAL CRÔNICA: CONHECENDO A EXPERIÊNCIA DA CRIANÇA
}

\author{
Chronic Renal Insufficiency: understanding the \\ child's point of view
}

\section{Insuficiencia Renal Crónica: conociendo la experiencia del niño}

Sheila de Souza Vieira ${ }^{1}$

Giselle Dupas 2
Noeli Marchioro Liston Andrade Ferreira ${ }^{3}$

\begin{abstract}
RESUMO
Esta pesquisa objetivou compreender a vivência da criança com insuficiência renal crônica e analisar o significado que ela atribui a esta vivência. Os referenciais que embasaram o estudo foram o Interacionismo Simbólico e a Teoria Fundamentada nos Dados, teórico e metodológico, respectivamente. Neste estudo qualitativo, utilizamos a entrevista consentida semiestruturada. Foram entrevistadas oito crianças de 7 a 14 anos. Emergiram oito categorias conceituais que delinearam a trajetória da criança perante a doença: "Descobrindo-se doente", "Sofrendo mudanças no dia-dia", "Sentindo que está prejudicando outrem", "Sofrendo com outros problemas", "Procurando acostumar-se", "Igualando-se às demais crianças", "Não sendo forte o bastante" e "Projetando o futuro". A adaptação a uma doença crônica na infância é um processo complexo que se modifica à medida que a criança e sua família superam enfrentamentos anteriores. 0 relato da criança é muito importante para identificarmos suas necessidades $e$ assegurarmos uma assistência mais humanizada.
\end{abstract}

Palavras-chave: Insuficiência Renal Crônica. Criança. Enfermagem Familiar.

\begin{abstract}
This research aimed to understand the child's experiences with Chronic Renal Insufficiency and analyze the significance it attaches to this experience. As a theoretical and methodological reference, it has been used, respectively, the Symbolic Interactionism and the Grounded Theory. Semi-structured interviews were used to collect the data, allowing us to explore the definitions exposed by each child. There were eight children interviewed, between the ages of seven and fourteen years old. Eight conceptual categories emerged that outlined the child's psychological changes when confronted with the disease: "Discovering the disease", "Suffering Daily Changes", "Feeling that he or she is being a burden to others", "Suffering with other problems", "Trying to get used to it", "Making himself equal to other children", "Not being strong enough" and "Planning the future". The process of adapting to a chronic disease during childhood is very complex and it changes as the child and his family, overcome the previous obstacles. Listening to the child is very impor tant for us to identify his needs and to assure compassionate assistance.
\end{abstract}

Keywords: Renal Insufficiency. Chronic. Child. Family Nursing.

\section{Resumen}

Esta investigación tuvo como objetivo comprender la experiencia de los niños con insuficiencia renal crónica y analizar la importancia que atribuye a esta experiencia. Los referenciales nos cuales se embasaron el estudio son el Interaccionismo Simbólico y la Teoría Fundamentada en los Datos, teórico y metodológico respectivamente. En este estudio cualitativo utilizamos la entrevista consentida semiestructurada. Fueron entrevistadas ocho niños de 7 hasta 14 años. Emergieron ocho categorías conceptuales que delinean la trayectoria del niño frente a la enfermedad: "Se descubrir enfermo", "Sufriendo cambios en el día a día", "Sintiendo que esta perjudicando a otros", "Sufriendo con otros problemas", "Buscando acostumbrarse", "Se igualando a los demás niños", "No siendo fuerte lobastante" y "Proyectando el futuro". La adaptación a una enfermedad crónica en la niñez es un proceso complejo que se modifica a la medida en que el niño y su familia superan enfrentamientos anteriores. El relato del niño es muy importante para que podamos identificar sus necesidades y asegurarle una asistencia más humanizada.

\footnotetext{
${ }^{1}$ Enfermeira. Graduada pela Universidade Federal de São Carlos. Ex-bolsista PIBIC/CNPq/UFSCar. .Brasil. E-mail: sheilasvieira@yahoo.com.br, ${ }^{2}$ Enfermeira, Professora Associada do Departamento de Enfermagem da Universidade Federal de São Carlos. Brasil. E-mail: gdupas@power.ufscar.br, ${ }^{3}$ Enfermeira, Professora Associada do Departamento de Enfermagem da Universidade Federal de São Carlos. Brasil. E-mail: noeli@power.ufscar.br
} 


\section{INTRODUCÃO}

As condições crônicas podem ser definidas como condições médicas ou problemas de saúde com sintomas e incapacidades associadas, que exigem controle em longo prazo ( 3 meses ou mais). Elas afetam pessoas de todos os grupos etários, socioeconômicos, étnicos, culturais e raciais. Nem sempre são incapacitantes, mas são suficientes para provocar limitações de atividades ${ }^{1,2}$. A duração e o risco de complicações exigem controle e cuidados permanentes devidos a possíveis sequelas que podem ocorrer, e essa é uma das dificuldades que a família pode enfrentar em relação às doenças crônicas, o que coloca em evidência o seu papel ${ }^{3}$.

0 indivíduo afetado por uma doença crônica sofre mudanças no estilo e qualidade de vida, acarretadas pela presença da patologia, da demanda terapêutica, do controle clínico e das hospitalizações recorrentes. As implicações da doença crônica na infância abrangem dificuldades estruturais e instabilidade emocional que atingem toda a família. A criança pode ter seu desenvolvimento físico e emocional afetado e apresentar desajustes psicológicos decorrentes do tratamento. Este gera

\section{MATERIAIS E MÉTODOS}

\section{Referencial Teórico e Metodológico}

Para compreender a vivência da criança renal crônica, optamos pelo Interacionismo Simbólico (IS), uma teoria das relações humanas difundidas por George Herbet Mead e seu seguidor e maior intérprete Herbert Blummer. 0 IS representa a particularidade do ser humano de interagir, interpretar, definir e agir no seu cotidiano de acordo com o significado que ele atribui à situação vivenciadå.

A metodologia de análise qualitativa eleita foi a Teoria Fundamentada NOS Dados (TFD), desenvolvida por Barney Glaser e Anselm Strauss, que tem seus fundamentos na perspectiva teórica do Interacionismo Simbólico. É um método de pesquisa que visa formular novos conceitos e teorias a partir dos dados levantados sobre o aspecto subjetivo das experiências sociais da pessoa. A coleta e análise dos dados acontecem concomitantemente através de um método comparativo constante 9 .

Chenitz e Swanson ${ }^{10}$ referem que esta metodologia, por ser uma forma de manejar os dados, é uma constante construção, que permite ao pesquisador parar em qualquer nível de análise dos dados e reportar o encontrado.

0 projeto de pesquisa foi aprovado pelo Comitê de Ética em Pesquisa da Universidade (Protocolo 0092.0.135.000-05) e pelo Setor de Educação Continuada da instituição em que as crianças realizavam tratamento. Foram convidadas a fazer parte da pesquisa todas as crianças que, no período de coleta de um ônus à família, demandando custos financeiros, alterações na rotina diária, sentimentos de aflição, tensão, insegurança e preocupação pelo medo de complicações e morte ${ }^{45}$.

A doença renal crônica tem alta morbidade e mortalidade, e sua incidência e prevalência vêm aumentando progressivamente, em "proporções epidêmicas" no Brasil e no mundo. 0 alto custo para manter os pacientes em tratamento renal substitutivo tem preocupado o governo. Estimativas apontam que há cerca de 3,1 milhões de brasileiros com algum déficit de função renal ( $1,7 \%$ da população), e por volta de dois milhões de pessoas teriam insuficiência renal crônica moderada, grave em fase terminal ${ }^{6}$. Em censo publicado em janeiro de 2006 pela Sociedade Brasileira de Nefrologia, estimase que há 70.872 pacientes em modalidades dialíticas no país, e, destes, 1.153 são pacientes com idade menor que 18 anos $^{7}$.

Sabendo que há um aumento no número de casos de crianças com patologias renais crônicas, que os custos com o tratamento são altos, e ainda que existem poucos estudos sobre o tema, objetivamos compreender a vivência da criança com insuficiência renal crônica e analisar o significado que ela atribui a esta vivência.

dados (de janeiro/2006 a julho/2007), estavam sendo atendidas no Ambulatório de Nefropediatria e na Unidade de Hemodiálise de um Hospital Escola do interior do Estado de São Paulo, com idade entre 7 e 12 anos, mas quatro crianças não quiseram participar. Outras duas, adolescentes de 14 anos, manifestaram interesse e foram aceitas. Havendo concordância da criança, os pais foram procurados, receberam esclarecimentos e, concordando com a entrevista, assinaram o Termo de Consentimento Livre e Esclarecido. No total, foram entrevistadas oito crianças (Quadro 1), sendo que duas delas foram entrevistadas duas vezes, uma por terem passado de tratamento conservador para diálise peritoneal e outra, de diálise peritoneal para hemodiálise.

\section{Local}

As entrevistas foram realizadas após o esclarecimento sobre os aspectos éticos da pesquisa, durante o período que antecedeu a consulta de retorno médico das crianças. Duas entrevistas, por preferência das mães, foram agendadas no próprio domicilio. Com algumas crianças estabelecemos um primeiro contato para facilitar a interação. No entanto, o fato de a maioria das crianças ir apenas uma vez ao mês à consulta de retorno e de morar em cidades distantes fez com que optássemos que a entrevista fosse realizada já no primeiro encontro. As entrevistas foram realizadas em local reservado, e quatro crianças preferiram realizá-la com a presença do responsável. 
Doença Renal Crônica: a experiência da criança.

Quadro 1 - Caracterização das crianças participantes da pesquisa segundo idade, sexo, outras complicações ou doenças e modalidade de tratamento. São Carlos, SP. 2006/2007

\begin{tabular}{|c|c|c|c|c|}
\hline $\begin{array}{c}\text { CRIANÇA } \\
\text { E N DA } \\
\text { ENTREVISTA }\end{array}$ & $\begin{array}{l}\text { IDADE } \\
\text { (anos) }\end{array}$ & SEXO & $\begin{array}{c}\text { OUTRAS COMPLICAÇÕES/ } \\
\text { DOENÇAS }\end{array}$ & $\begin{array}{l}\text { MODALIDADE DE } \\
\text { TRATAMENTO }\end{array}$ \\
\hline E.C.F. (1) & 8 & M & Realiza sondagem vesical & $\mathrm{TC}^{1}$ \\
\hline A.P.D.C. (2) & 10 & $\mathrm{~F}$ & Escoliose e paralisia dos MMII & $\mathrm{TC}$ \\
\hline G.J.B. $(3$ e 10$)$ & 11 & M & $\begin{array}{c}\text { Síndrome de Alport /deficiência } \\
\text { auditiva }\end{array}$ & $\mathrm{TC}$ e DP ${ }^{2}$ manual \\
\hline C.F.R.Z. (4 e 6) & 8 & $\mathrm{~F}$ & - & DP manual/máquina \\
\hline J.F.C. (5) & 7 & $\mathrm{~F}$ & - & DP manual e hemodiálise \\
\hline C.C.M. (7) & 14 & $\mathrm{~F}$ & $\begin{array}{c}\text { Doença renal crônica secundária à } \\
\text { quimioterapia } / \mathrm{TU}^{3} \text { Askin }\end{array}$ & $\mathrm{TC}$ \\
\hline W.D.T.F. (8) & 8 & M & - & DP manual e hemodiálise \\
\hline V.A.C.B. (9) & 14 & $\mathrm{~F}$ & - & DP manual \\
\hline
\end{tabular}

${ }^{1} \mathrm{TC}=$ Tratamento conservador, ${ }^{2} \mathrm{DP}=$ Diálise peritoneal, ${ }^{3} \mathrm{TU}=$ Tumor de Askin

\section{Instrumentos}

0 instrumento adotado foi o roteiro de entrevista semiestruturado com questões abertas do tipo: "Como é para você conviver com a doença renal?", "Fale-me sobre as dificuldades encontradas no dia-dia", "Gostaria que você me contasse o que é mais difícil/ruim." À medida que estas questões foram resolvidas, outras foram formuladas. Frases como: "como assim?" "me fale mais sobre isso", foram utilizadas no sentido de aprofundar o tema.

As entrevistas foram gravadas e transcritas na íntegra. As informações foram analisadas minuciosamente com o propósito de apurar os dados relevantes, de verificar as categorias emergentes e de observar que outros dados deveriam ser buscados. Desta forma, os sons viraram escritos, a escrita virou códigos, os códigos formaram subcategorias, as subcategorias geraram categorias, e estas revelaram aspectos importantes do viver da criança, bem como as lacunas que há de se desbravar.

\section{RESULTADOS}

A experiência da criança é percebida como uma trajetória. Oito categorias conceituais emergiram a partir do seu relato: "Descobrindo-se doente", "Sofrendo mudanças no dia-dia", "Sentindo que está prejudicando outrem", "Sofrendo com outros problemas", "Procurando acostumar-se", "Igualando-se às demais crianças", "Não sendo for te o bastante" e "Projetando o futuro", compostas por subcategorias que representam sua experiência nessa vivência.

Em "Descobrindo-se doente", a criança conta a sua experiência em vivenciar o início do problema renal e as mudanças ocorridas. Percebe que estão Acontecendo coisas diferentes de modo frequente e intenso, que sugerem haver algo errado. A criança e seus pais vão à busca de respostas,
Procurando ajuda, fazem consultas médicas, exames, e acabam por descobrir a doença.

Quando eu era bebezinho (...) Eu tava fazendo xixi, ficava inchada, daí descobriram que eu tinha. E4.

Daí ele já começou a correr atrás... daí eles foram e vieram aqui no Hospital $X$ pra saber sobre isso... daí o médico falou que o rim poderia ter atacado a audição; daí eles queriam fazer outra biopsia, daí depois de um tempo, nós constatamos, fez a biópsia e descobriu o problema. E3

A criança vê sua Vida começando mudar não apenas no início da doença, mas no início de cada modalidade de tratamento, que é permeado por inúmeras alterações e adaptações. Por conseguinte, o sentimento gerado pelos procedimentos, hospitalização, infecção e medo da dor e da morte define a subcategoria Tendo medo do desconhecido que é repleta de insegurança, incerteza e temor.

A primeira vez eu fiquei com vontade de chorar?! Daía moça me pegou, eu abracei a minha mãe com os olhos cheinhos de lágrima querendo chorar, mas eu não chorei, daí eles me deram a inalação. E4

Antes de fazer tava com medo de morrer. Ainda bem que não morri. E1

A categoria "Sofrendo mudanças no dia-dia" conta sobre as mudanças no estilo de vida ocorridas após a doença renal. Seu mundo muda bruscamente; tudo que nunca esperava acontecer com ela sobrevém. Sentir-se mal devido à enorme restrição alimentar é o sentimento dela ao ser proibida de comer uma variedade de alimentos antes possíveis, ter que comer sem sal e ter a ingestão hídrica regulada. 
O mais difícil? É a alimentação (...) não posso comer muito feijão, e as coisas que eu gosto de comer, eu não posso comer muito. Isso é mais difícil. E2

Mudou tudo! Não posso comer com muito líquido, não posso comer coisa salgada, não posso comer salgadinho, só posso comer coisa doce (...) me sinto ruim. Ruim porque a comida é sem sal. Não sente gosto de nada. E4

Estranhei porque a minha carne predileta é a vermelha! Então foi justo a carne que mais gostava. E7

Ser ruim tomar muitos remédios é conviver diariamente com uma "avalanche" de remédios para controlar o problema renal, a pressão alta e as carências nutricionais. Sofre com os efeitos colaterais, com os custos trazidos à família, e por não obter melhora significativa.

Assim, porque é chato um monte de remédio... às vezes acha que o exame vai dar bom porque você tá tomando, ás vezes não adianta, dá ruim, aí tem que tomar mais remédios. Ainda tem remédios que faz mal pra mim, eu não gosto muito (...) Tinha um aí que era mó caro, uns 700, 800 reais. Eu fui tomar ele, tomei uma semana aí eu passei mal. Não comia, vomitava, me dava dor de cabeça. Nossa é muito ruim... E9

Interromper as atividades diáriasé ter que parar de brincar, interromper o sono, deixar o que estava fazendo para realizar os procedimentos e tomar remédios. Interromper as atividades escolare é erder aulas, ou ter que sair mais cedo e chegar atrasado à aula devido às consultas ao médico, ao mal-estar, à adaptação quando da colocação do cateter ou pelo medo de se machucar.

Ás vezes, quando eu saio com meu pai, chego muito cansado, e eu num quero tomar remédio que eu fico com sono e já quero dormir. Daí ele vai lá e já acende a luz, aívai me acordar pra tomar remédio. E3

Na escola eu não venho mais, porque tô vindo aqui.

(...) Minha mãe tem medo do moleque puxar o aparelho na hora do recreio, e aí a criança quer brincar com a gente, pode machucar, pode puxar. E5

Mudar no brincar é não poder brincar com os bichos de estimação, de pelúcia, não poder correr, nadar. É deixar de participar das aulas de educação física. É a mudança do ativo para o contemplativo que a deixa triste, que a faz se sentir diferente e por vezes com raiva.

Na escola eu não posso fazer educação física, não pode correr, nem ficar jogando bola, eu não posso
(...) eu fico parada (chorosa) fico vendo as outras crianças brincar e fico lembrando quando eu brincava. E4

Podem empurrar, cair no chão, bater o cateter, perigoso daí! (...) antes podia brincar do que eu quisesse, podia ir em qualquer lugar, nadar, podia fazer qualquer coisa, jogar bola, agora não! E10

Ser incomodada pelo tratamentoé a vivência do desconforto e dor no transcorrer da doença. É sentir-se importunada pela equipe de saúde, pelo cancelamento e remarcações das consultas, pela realização dos procedimentos, por ser alojada em um ambiente desconfortável, e por ser impedida de ir a lugares que gostaria.

PÉSSIMO! De ter problema no rim? MUITO RUIM! Porque problema no rim é ruim. Porque é ruim fazer hemodiálise. É ruim de dormir lá.... tem barulho, a televisão fica ligada muito alto. E o condicionador (ar condicionado) é muito alto... Elas erguem a televisão mais alto e não dá vontade nem de dormir. E8

Dá frio, bastante frio em mim. Daí tem que tomar banho, e às vezes minha mãe nem deixa eu tomar banho pra não gastar muita força, daí tenho que ir pra escola com frio, é ruim... porque se esquentar a bolsa ela dá muita dor, pior que o frio, e se não esquentar dá frio, mas não é tão pior do que esquentar ela. E10

Não gostar de esperar pelo médicoé o desabafo de ter que aguardar horas para fazer a consulta médica, depois de ter faltado à aula, acordado cedo e viajado horas.

... lá em cima eu esperava. Mandava tá 8 horas lá, e chegava quase 10 horas. Aí ficava esperando. Ficava assistindo $T V$, andando pra lá e pra cá (...) Ah eu não gosto. Mas tem que ter paciência né? Pra esperar ele... Você não pode saber por que eles tão demorando. Então acostuma. E9

Temer a infecção é imaginar a possibilidade de piorar seu problema e prejudicar a sua saúde caso contraia uma infecção e suas consequências, já vivenciadas ou presenciadas. A criança começa a perceber a importância do adequado funcionamento da diálise, contando em sua linguagem simples sobre a dependência de sua saúde da higienização e limpeza necessária, Valorizando cada passo dos procedimentos.

O mais difícil? É porque aqui no Hospital $X$, quando vai ligar abre a porta... então não pode abrir, senão entra um monte de bactéria aqui e pode me dar um monte de infeç̧ão... aí eu tenho que trocar o cateter e daí não pode abrir a porta lá do meu 
quarto. Daí fica batendo assim: -pá pá pá. Daí a minha mãe fala: -não pode, não pode! Daí depois minha mãe fala: -pode entrar (...) então não pode abrir, e não pode ficar muita gente no quarto... e aqui no Hospital $X$ fica. E4

Porque eu um dia eu tava brincando, eu fui ligar a diálise, saiu sangue porque eu tinha acabado de brincar. Nossa que susto! Pensei que já estava infeccionado. Ai se tivesse, né?! Aí voltava tudo de novo pra fazer. Aífiquei com medo. Sorte não era... Ah eu ouvi uma história de um médico que matou uma criança por causa de uma infecção aí. Deu medo só em pensar nisso (...) ah não prefiro ficar assim pro resto da vida. E9

A minha mãe lava a mão, 10 vezes assim, aípega o paninho e faz assim... E a hora de ligar tem que estar tudo fechado, pra poder ligar eu. E tem que pôr a máscara. E4

Em "Sentindo que está prejudicando outrem", a criança deixa transparecer sua preocupação com a família e com outras pessoas, percebe as dificuldades corriqueiras do lar e se vê como um problema para os outros. Desabafa que sua doença não se restringe a mudar sua vida, mas pior, outros têm que "pagar" por/e com ela. Pensa na possibilidade de o doador para seu transplante ser um membro de sua família, e gerar riscos a este.

É, mudou pra todo mundo... por causa de mim, meus pais, eles tem que comer arroz, feijão sem sal. . . porque a gente tem que sair. Se a gente vai na casa dos outro tem que fazer sem sal pra mim comer? Se for com sal eu não posso. Vai fazer sem sal e todo mundo vai ter que comer sem sal por causa de mim? E3

... daí eu prefiro (transplantar)... só que eu acho ruim se meu pai dar, doar um rim pra mim e ele ficar doente daí, isso eu não sei... eu estou com dúvida. (...) É ficar faltando um rim pra ele. E10

"Sofrendo com outros problemas" é a experiência da criança com situações/doenças que para ela são muito mais limitantes, o que a leva a sublimar o problema renal. Situação apontada em Vivenciando problemas maiores.

Eu não consigo andar porque quando era bebezinha, eu fiquei na UTI. . . porque o médico fez uma cirurgia tão errada que paralisou eu. Da cintura pra baixo eu não sinto nada. (...) Aí eu não ando (...)só queria operar minha coluna... nem precisava andar, se a coluna não entortasse já tava bom. E2
Na época... eu nem me toquei muito porque eu já tava tão acostumada com médico, tal. . tomava sempre remédio que nem me importei... também, pelo que eu já passei não é nada... o mais difícil foi a perda do meu cabelo... atémais que a descoberta da doença! (...) eu acredito que pra todas as meninas da minha idade, que tem o xodó pelo cabelo como eu tinha... eu acho que é a perda do cabelo. E7

Na escola é importunada pelo barulho e bagunça. Isso provoca distração e atraso na realização das suas tarefas, comprometendo seu rendimento escolar. É importunada com as constantes e repetitivas perguntas sobre a doença, Sentindose incomodada pelos colegas. Vivencia situações de zombaria, desrespeito, e exclusão social devido às suas deficiências. Sentese diferente, magoada e reage comumente com fuga e recolhimento, Ressentindo-se com o preconceito e a discriminação.

Queria fazer computação, mas a escola de computação perto da minha casa é de escada e a cadeira de rodas não sobe (...) a professora fez um projeto de ajudante e vigia do dia... um aluno por dia ajudava vigiar o recreio. Quando chegou na minha vez a professora pulou meu nome e escalou outra criança. (...) eu perguntei porque disso, e disse que eu não andava com as pernas, mas podia muito bem andar com a cadeira de rodas, mesmo sendo um pouco mais devagar mas eu andava (...) ela preferiu terminar o projeto do que deixar eu ser a vigia (...) sempre vai ter gente que gosta e gente que não gosta de você. E2

Ah era um saco. Todo mundo, vinha um monte fazendo as mesmas perguntas. Vinha um e perguntava, daqui a pouco vinha outro. Gente,chega! Pergunta pra quem já respondi. É chato ficar respondendo. E9

Era ruim usar fralda, é melhor fazer cateterismo porque é chato usar fralda. Me chamam de bebê, fraldinha, ainda me chamam de anãozinho de jardim só porque eu sou o mais pequeno da classe, da escola.

$\mathrm{Na}$ escola eu estou um pouco atrasado, pouco rápido, lento. Tem muita gente que me chama de tartaruga lenta, eu não gosto. Eu paro algumas vezes, eu faço e paro. Fico distraído, meus amigos me fazem distrair. Nas tarefas (em casa) sou rápido porque não tem ninguém. Mas na escola sou (lento) porque tem muita gente. $E 1$

"Procurando acostumar-se" é a categoria que demonstra os meios que a criança utiliza para enfrentar seu problema e 
adaptar-se ao novo estilo de vida. Explicando a doença para os outros, responde às perguntas e curiosidades dos colegas, e deixa os professores a par de suas necessidades porque sabe, que quando as pessoas estão cientes da sua doença, podem ajudá-la sempre que precisar, o que a faz se Sentir ajudada quando conta sobre o problema.

A maioria das crianças sabe. Porque é bom eles saberem para ajudar quando precisar deles. Se estou passando mal, podem ajudar a ir falar... Eles sempre fazem isso quando eu estou com dor, eles vão lá na diretoria. E3

Esforçando-se para acompanhar a classe com a ajuda das professoras e amigos, procura minimizar os efeitos que a doença/tratamento tem sobre o rendimento escolar, estuda mais em casa para recuperar o perdido, pede emprestado as anotações, senta-se na frente; no entanto, isso não substitui a explicação da professora, mas já ameniza. Algumas crianças dão continuidade aos estudos dentro do hospital.

Eu peço para os meus irmãos levarem meus cadernos para minha amiga, ela copia minha lição, eu peço pra eles trazerem meu trabalho, aífaço em casa. E9

Procurando adaptar-se à dieta e compensar as restrições, acostuma-se a comer coisas que não gosta e com apenas "um pouquinho de sal", come em menor quantidade, ou escolhe outra opção. Às vezes, os pais permitem infringir parcialmente as proibições e compartilham dessa estratégia de enfrentamento.

Uma vez por mês eu compro e como. Uma vez por mês não vai fazer mal, só não pode comer todo dia, aíque é ruim (...) ou quando não posso eu pego uma fruta para aliviar um pouco senão eu não aguento... E9

No movimento Aprendendo a conviver com os remédios, a criança passa a encará-los como algo necessário, benéfico e essencial à sua saúde, porque com eles a doença é controlada. Vendo um lado bom no tratamento, percebe que este possibilita realizar coisas que em algum momento teve que interromper, que a aproxima da família que passa a direcionar mais tempo e atenção para o seu cuidado.

Ah eu gosto né... que também o remédio me ajuda a eu melhorar minha saúde, essas coisas. E2

Era a maior dificuldade, até eu aceitar que tinha que tomar. Porque não era assim uma gripe que dois dias passa. Tinha que tomar! Se não tomasse aquele dia, um dia ia ter que tomar! Aí comecei aceitar. E7

Ah eu acho que antes (da diálise) era mais chato! Porque antes ninguém nunca ligava pra mim, eu era mais sozinho, só que eu podia comer um pouco mais estas coisas (...) podia fazer qualquer coisa e agora não! Agora já tá todo mundo mais ligado em mim (...) Agora eles não tão deixando eu só assim, eles estão mais perto de mim sabe... Ah minha vó, meu vô, meus primos são tudo gentis agora comigo... Agora minha vó compra tudo que eu quero, faz todo meu gosto (...) e também eu pensei que eu não ia poder mais brincar, jogar bola, não ia poder mais sair pra escola, falar com meus amigos. Daí depois o tempo foi passando, eu tô correndo, tô brincando, tô soltando pipa, jogando bola, tô fazendo tudo. E10

Ter preferências no tratamento mostra as preferências da criança por alguns procedimentos a outros, de horários e locais para realizá-los que a incomodem menos, que permitam mais "liberdade" e causem menos dor, medo e desconforto.

Aqui é muito chato! E lá na minha casa eu fico ouvindo som e aqui não... aqui é chato porque a enfermeira fica enchendo, enchendo o saco. E4

Quando tá na máquina (hemodiálise) ela deixa eu beber tudo e comer a gelatina e o lanche. E5

A categoria "Não sendo forte o bastante" representa as situações em que o desejo e a vontade vencem por um momento a "batalha". Não conseguindo se controlar, desobedece as regras, a dieta, anseia pelo proibido, não resistindo por vezes.

Ah pra falar a verdade... eu também bebo escondido. Aíhoje eu bebi um pouco de água! (Mãe: bebeu?). . . A mulher que deu... E8

Ah porque eu fico com vontade de comer e não pode (...) Eu tento fazer, às vezes eu não consigo muito porque a maioria das coisas que eu gosto eu não posso comer. E3

Desafia os mais velhos, Sabendo que os pais têm um limite, insiste para que o seu desejo seja realizado por saber que os pais ouvem os pedidos dela até certo ponto. Sente que tem um limite que pode ser explorado até a hora que precisa obedecer para não sofrer as consequências.

Se você falar três vezes e eles falarem: - Não!, Aíé que eles não vão dar... Mas se você falar duas vezes e eles falarem: -Sim!, daí você pode pegar...E3

Por vezes, opta pelo enfrentamento, Sendo repreendido pela família, o que a revolta e deixa com raiva. Ela acha que sabe o que deve ou não fazer, quais as consequências, e julga não necessária essa conduta dos mais velhos; mas também se sente mal quando deixa os pais bravos. 
Doença Renal Crônica: a experiência da criança.

Eu não gostava porque meu pai pegava muito no meu pé. E eu não gosto que as pessoas fiquem pegando no meu pé, sabe?! Eles ficaram bravos comigo porque eu também não gostava de tomar os remédios. E7

"Igualando-se às demais crianças" é a categoria em que a criança olha para a doença de um jeito diferente, percebendo a si mesmo e seus problemas de forma minimizada, considerando que eles não a impossibilitam de viver como as outras crianças. É tentar sentir-se mais feliz e conformada, Ajudando nas tarefas domésticas, Brincando como toda criança, Procurando não enxergar sua merenda como diferentee Podendo fazer algumas escolhas na alimentação.

E eu ajudo a minha mãe lá na minha casa (...) Eu faço comida, eu pego tomate, tempero bife....E4

Não, nem sente nada, num sinto mais nada dele (cateter). Ele só fica pulando assim quando eu corro, aí eu amarro ele assim bem amarradinho, daí ele fica bem preso, daí dá pra eu brincar sossegado. E10

Só que as frutas que eu mais gosto pode comer, $e$ as frutas que eu não gosto não pode (...) Melancia também eu adoro bastante, mas pode comer também, mas não exagerar. Mas eu posso comere eu como. E3

Na sala de aula é normal como as outras crianças (...) Eu brinco tanto que eu esqueço de comer. E2

A subcategoria Querendo sentir-se normal demonstra o desejo que as pessoas não a enxerguem como diferente. Exclama constantemente "normal, só não posso algumas coisas", num processo de querer também se reconhecer sem limitações tão significativas.

Na escola é tudo normal, posso brincar normal, na sala de aula é normal como as outras crianças (...) não mudou nada, continuei normal. Aniversario é normal, como que eu fosse uma criança normal, normal... Ah eu vou onde eu quero, normal. . . eu não vou nos outros porque eu não gosto muito (...) eu me sinto bem, normal, meus pais trataram normal, tudo normal (...) eu não ando, mas eu me sinto bem. E2

Em "Projetando o futuro", a criança projeta o amanhã levando em conta o que faz hoje. Tendo consciência de suas ações, sabe que tudo tem consequências que recairão sobre sua saúde; que é melhor seguir a dieta e colaborar com o tratamento. Numa postura introspectiva, ela avalia seu proceder, as possibilidades futuras, Procurando seguir o tratamento.
Esc Anna Nery Rev Enferm 2009 jan-mar; 13 (1): $74-83$

Penso bastante né?! Quando nas horas que estou comendo as coisas que não posso daípenso né? E3

Foi difícil porque foi uma teimosia minha que afetou meu rim. Pediam sempre pra eu tomar água, só que eu não tomava. Então por uma teimosia minha prejudicou. Só depois que terminei a quimio,eu vi que se tivesse tomado água, já tinha me livrado de todos remédios. Porque agora só tomo remédio para o rim. E7

0 medo de ter que vir a realizar procedimentos mais agressivos, dolorosos e arriscados também faz com que procure seguir as orientações médicas e de enfermagem e se cuidar.

Eu faço do jeito que ela (médica) mandou, tomo remédio, faço tudo que tenho que fazer cer tinho (...) Ah eu me seguro, tenho que segurar senão...E9

Eu comecei a tomar o remédio, a aceitar que tinha que tomar, porque eu tinha muito medo de ter que fazer hemodiálise. Porque tinha uma mulher lá na minha cidade que ela fazia. Então os braços dela eram cheios de marca e tal, e eu não queria aquilo pra mim! Por isso, eu comecei a tomar remédio, a tomar bastante líquido (...) eu morria de medo de ter que fazer! Porque a gente nunca quer o pior pra gente né? E7

Querer protelar o enfrentamento é projetar para o futuro situações que no momento não se sente capaz de aguentar por considerar-se frágil.

Também tenho muito medo de fazer transplante e o outro (hemodiálise) (...) porque eu sou muito pequeno e talvez eu não possa aguentar. Equando eu ficar moço, posso ficar mais forte, posso até aguentar. Ah, no futuro até que eu posso aceitar. . . não vou ter tanto medo quanto agora. E3

Preferir transplante a outros tratamentosé quando a criança escolhe (como se pudesse fazer isso) não ter que passar pela diálise ou hemodiálise, não sentir dor nem ser mais prisioneira da "máquina", mesmo tendo que tomar "um remédio que irá engordar". Vislumbra que o Transplante a torne normal, livrandoa das restrições. É a realização de um sonho, não dela apenas, mas da família e amigos. É esperar do transplante tudo que ela mais quer: poder brincar, correr, nadar, pular, cair... poder comer de tudo, em maior quantidade e variedade, exceto carambola... poder beber tudo, água... parar de tomar remédios... ser o máximo... ser feliz... ser normal!

Vai poder beber tudo, poder beber água, guaraná não, só suco. Ir na escola. Minha mãe vai dar E5

Oh eu espero que eu ganhe um rim novo de meu pai, e de alguém da fila aí que possa me doar e que 
eu siga que nem uma pessoa normal. Nósfez exame, pra ver se podia doar. Deu compatível (...) daí eu acho que vou tirar este cateter né, e vou seguir normal na vida. E10

Nossa, um monte! Já veio um monte de rim pra mim! Eu não podia porque vou fazer cirurgia na bexiga. Eu? Quero! Porque quero brincar de muita coisa, guerrinha, pular corda, andar de bicicletão, CAIR.) E8

Dá vontade de parar de tomar remédio logo. Fazer transplante logo. Pra mim poder comer de tudo (...) eu vou fazer muita coisa (...) vou poder correr, poder brincar, poder viver uma vida normal, menos poder brincar na terra, e comer carambola (...) Meu transplante vai ser o máximo! E1

\section{DISCUSSÃO DOS RESULTADOS}

A adaptação a uma doença crônica na infância é um processo complexo que a criança enfrenta a cada dia, do diagnóstico a cada nova modalidade de tratamento. A forma de lutar vai se modificando à medida que ela supera enfrentamentos anteriores.

Conviver com restrições alimentares, remédios, mudanças no brincar, interrupções das atividades diárias e escolares e 0 temor quanto à infecção, progressão da doença e morte faz com que ela apresente sentimentos de tristeza, irritabilidade, ansiedade e insegurança, o que foi apreendido por outros autores ${ }^{11-13}$. Estes se manifestam dependendo do contexto em que tais situações ocorrem, isto é, local, pessoas, interações, socialização. Algumas das crianças consultadas, além do problema renal, vivenciam limitações motora e auditiva e déficit de crescimento, que por si só já as levam a se sentirem diferentes e inferiores. Assim, quando se deparam com zombarias e exclusão das demais crianças e até de adultos, sofrem ainda mais.

Dentre as atividades diárias, a escola tem destaque nesta faixa etária, fazendo com que as modificações sejam sentidas mais fortemente. As relações sociais ocorrem neste espaço, e a criança sente falta delas. Pereira ${ }^{11}$ relata que a instabilidade física, emocional, social e familiar torna a criança vulnerável ao mau desempenho escolar.

Percebemos que para a criança é muito mais difícil não comer, não brincar ou realizar outras atividades quando ela está em um meio em que esses fatos estão acontecendo. Entendemos que, à luz do referencial do IS, o significado das coisas resulta da interação social que os seres humanos estabelecem uns com os outros e com o meio, o que se confirma na experiência dessas crianças.

A criança percebe que sua vida se tornou mais restrita, não permitindo que ela faça várias coisas como antes; também que houve mudanças significativas em sua rotina diária e na dinâmica familiar. Percebe, ainda, que seus pais abdicaram de muitos de seus sonhos, vontades e preferências para cuidar dela; preocupa-se em vê-los sobrecarregados e sofrendo; em atingir a vida dos irmãos privando-os de várias coisas; em diminuir as atividades de lazer da família, gerando um isolamento social; em ser um fator de desvio das finanças e do tempo por serem muitos os cuidados que seu tratamento demanda. Tais percepções também apareceram em outras pesquisas ${ }^{4,5}$. Esse isolamento social da família a deixa mais sensível e vulnerável aos transtornos emocionais no enfrentamento dos problemas decorrentes da enfermidade ao perceber que sua doença traz ônus não só para ela, mas que todos "pagam" com e por ela.

Tomar o lugar do outro e entender suas dificuldades tem sido uma habilidade que crianças cronicamente doentes possuem mais do que as crianças saudáveis, sendo possível que elas desenvolvam a habilidade empática mais precocemente do que seus pares normais, o que foi considerado como um resultado positivo dessa experiência. ${ }^{5}$.

Embora a criança renal crônica saiba das suas limitações, procura superar os momentos difíceis e tenta viver uma vida bem próxima à de uma criança sadia. Desenvolve estratégias de enfrentamento para burlar o estereótipo de doente e negar suas diferenças e fragilidades. Quer ser e estar o mais próximo da normalidade, mesmo sabendo que não é essa a verdade . Compara seus problemas com os de outras crianças, acreditando que o problema do outro é maior e mais complexo que o seu.

A criança percebe aspectos positivos no tratamento que tornam sua qualidade de vida melhor: a atenção e maior tempo que ela tem com os pais e família; a amizade com a equipe de saúde e demais pacientes que a fazem sentir-se importante; 0 alívio da dor e dos sintomas; e a realização de atividades que não conseguia ou podia antes.

As preferências por determinado procedimento, horário e local para realizá-lo variam de criança a criança, e estão ligadas às suas particularidades, informações sobre os mesmos, seus medos e suas experiências anteriores. Para algumas crianças, a diálise no domicílio passa a ter aspectos positivos no sentido de não precisar se deslocar para o hospital, de possibilitar a realização de outras tarefas e atividades por elas e pelos pais enquanto elas dialisam e de interferir menos na sua rotina diária. Elas se queixam também de serem importunadas, apressadas e corrigidas pela equipe de enfermagem quando está no hospital. Conseguir a máquina de diálise para realizar o tratamento em casa é considerado positivo para a criança porque esta oferece mais liberdade para toda a família, restringea apenas de noite e interfere menos nas suas atividades escolares. Em contrapartida, algumas crianças relataram suas preferências pela hemodiálise, justificando que esta traz benefícios, isto é, poder comer e beber durante o procedimento, e ainda o fato de ter uma equipe dando suporte e assistência caso ela precise. As que estão doentes há mais tempo ou que possuem informação e/ou vivência acerca das diversas modalidades de tratamento esperam pelo transplante renal, 
por saberem que é a próxima etapa e que pode garantir melhor qualidade de vida.

Buscando protelar o enfrentamento, a criança desenvolve a percepção de que precisa se ajudar, desenvolver responsabilidade de colaboração com seu tratamento, o que a leva a optar de algum modo por se submeter a ele. Todavia, ter o direito de fazer escolhas simples, como horário, posição, local e alternativas, faz com que a criança se sinta de alguma forma autônoma e importante.

A criança finaliza seu relato contando seus sonhos e sua projeção do futuro: quanto à possibilidade de experimentar 0 alívio das proibições e restrições dietéticas; poder brincar em qualquer lugar; realizar suas atividades diárias e escolares sem interrupções; enfim, esperar que sua vida mude completamente com a realização do transplante no futuro. Nesse sentido, percebemos que ela anseia e cria expectativas que muitas vezes não condizem com a realidade. Para a maioria, transplantar é tornar-se normal, é ser curada. Essa idealização a respeito do transplante pode causar um prejuízo emocional de grandes proporções futuramente. Concordamos, portanto, com alguns autores ${ }^{11-14}$ que dizem que se passaram anos de modernização das técnicas, procedimentos, aparelhos e

\section{CONSIDERAÇÕES FINAIS}

Concluímos que a experiência das crianças doença renal é ampla e complexa, que cada uma delas vivencia situações comuns e diferentes umas das outras, e a partir disso atribuem significados diversos à experiência. 0 relato de sua trajetória com a doença nos possibilita identificar suas potenciais necessidades e melhor compreender sua vivência, permitindo prestar uma assistência mais humanizada e integral.

Muito há ainda que se conhecer e mais investigações precisam ser realizadas, uma vez que a condição socioeconômica, cultural e educacional, o suporte social e as características individuais e familiares atribuem diferentes formas de enfrentamentos e respostas diante do processo

\section{REFERÊNCIAS}

1 - Elsen I, Marcon SS, Silva MRS, organizadoras. 0 viver em família e sua interface com a saúde e a doença. Maringá (PR): Ed Universidade Estadual de Maringá; 2002.

2 - Fráguas G, Soares SM, Silva PAB. A família no contexto de cuidado do portador de nefropatia diabética. Esc Anna Nery Rev Enferm 2008 jun; 12(2): 271-7.

3 - Ribeiro NRR. A família enfrentando a doença grave da criança. In: Elsen I, Marcon SS, Silva MRS, organizadoras. 0 viver em família e sua interface com a saúde e a doença. Maringá (PR): Ed Universidade Estadual de Maringá; 2002. v. 1, p. 199-220.

4 - Silva LF, Guedes MVCG, Moreira RP, Souza ACC. Doença crônica: 0 enfrentamento pela família. Acta Paul Enferm 2002; 15(1): 40-7.

5 - Castro EK, Piccinini CA. Implicações da doença orgânica crônica na infância para as relações familiares: algumas questões teóricas. Psicol Reflex Crit 2002; 15(3): 625-35. medicamentos, no entanto, nesse período, inúmeras crianças se tornaram renais crônicas sem, contudo, modificar a vivência dos medos, angústias e expectativas diante da concretização da "volta à normalidade".

Mostra-se, portanto, necessário prosseguir com contínua transmissão de informações e orientações no transcorrer do tratamento, investigando suas dúvidas e novas situações, a fim de ajudar a criança e família. 0 entendimento da doença e do tratamento é imprescindível, porque os motiva a seguir, minimizando a insegurança e medos, aumentando sua adesão na participação dos cuidados ${ }^{15}$.

Alguns autores comentam que a maneira como a assistência vem sendo prestada tem sido questionada por se mostrar insuficiente para a integralidade do cuidar ${ }^{5,11,14,16}$. A doença renal crônica acarreta ônus à qualidade de vida do doente e da família, que apresentam menores escores nos domínios dos aspectos físicos, emocionais e vitalidade. As atividades cotidianas são comprometidas com o tempo sendo, portanto, necessário que a equipe de saúde avalie esses aspectos e promova transformações condizentes com a realidade e previna o comprometimento dessas atividades ${ }^{16}$.

saúde-doença. Cada estágio da doença renal tem suas características, imposições e limitações, que precisam ser conhecidas com maior profundidade, visando instrumentalizar o cuidado individualizado a esta clientela.

Um chamado em especial é feito à Enfermagem, sobre a aproximação entre o enfermeiro, a família e a criança, para facilitar a compreensão da situação e possibilitar a ajuda na resolução dos problemas. Dando voz também à criança, a Enfermagem abre espaço para que haja compreensão de suas vivências, colaborando para que ela se sinta mais segura e confiante.

6 - Sesso R. Epidemiologia da doença renal crônica no Brasil. In: Barros E et al. Nefrologia: rotinas, diagnósticos e tratamento. $3^{\mathrm{a}} \mathrm{ed}$. Porto Alegre (RS): Artmed; 2006. p. 39-46.

7 - Sociedade Brasileira de Nefrologia. Amostragem dos centros de diálise do Brasil [citado 06 dez 2007]. Disponível em:http:// www.sbn.org.br/Censo/2006/Amostragem.ppt\#7

8 - Blummer H. Symbolic interacionism: perspective and method. Berkeley(USA): University of California; 1969.

9 - Glaser BG, Strauss AL. The discovery of grounded theory: strategies for qualitative research. New York(USA): Aldine de Gruyter; 1967.

10 - Chenitz WC, Swanson JM. From practice grounded theory: qualitative research in nursing. California (USA): Addison-Wesley; 1986. 
Doença Renal Crônica: a experiência da criança.

11- Pereira SR. Qualidade de vida da criança renal crônica submetida ao tratamento por diálise peritoneal intermitente: estudo de caso [dissertação de mestrado]. São Paulo (SP): Universidade Federal de São Paulo; 1993.

12- Vieira MA, Lima RAG. Crianças e adolescentes com doença crônica: convivendo com mudanças. Rev Latino-am Enfermagem 2002; 10(4):552-60.

13- Diniz PD, Romano BW, Canziani MEF. Dinâmica de personalidade de crianças e adolescentes portadores de insuficiência renal crônica, submetidos à hemodiálise. J Bras Nefrol 2006; 28(1): 31-8.
14 - Setz VG. 0 transplante renal sob a ótica das crianças portadoras de insuficiência renal crônica em tratamento dialítico: estudo de caso [dissertação de mestrado]. São Paulo (SP): Universidade Federal de São Paulo; 2004.

15 - Bastos MG, Barros W, Reis R, Almeida EC, Mafra D, Costa DM et al. Doença renal crônica: problemas e soluções. J Bras Nefrol 2004; 26(4): 202-15.

16 - Martins MRI, Cesarino CB. Qualidade de vida de pessoas com doença renal crônica em tratamento hemodialítico. Rev Latino-am Enfermagem 2005; 13(5): 670-76. 